University of South Florida

DIGITAL COMMONS

@ UNIVERSITY OF SOUTH FLORIDA
Digital Commons @ University of South Florida

June 2021

\title{
Concise Natural History of East and West Florida
}

\author{
Bernard Romans
}

Follow this and additional works at: https://digitalcommons.usf.edu/early_visions_bucket

\section{Recommended Citation}

Romans, Bernard, "Concise Natural History of East and West Florida" (2021). Early Visions Bucket. 41.

https://digitalcommons.usf.edu/early_visions_bucket/41

This Article is brought to you for free and open access by the Early Visions of Florida at Digital Commons @ University of South Florida. It has been accepted for inclusion in Early Visions Bucket by an authorized administrator of Digital Commons @ University of South Florida. For more information, please contact digitalcommons@usf.edu. 


\section{Early Visions of Florida}

Poetry • Stories • Chronicles from an American Borderland

\section{Bernard Romans, A Concise Natural History of East and West Florida}

Bernard Romans (b.1720) was born in the Netherlands, emigrated to America around 1757, and after a life of some controversy, died at about the age of 64. Romans, who spent sixteen years in North America (not all times, places, and activities accurately recorded), demonstrated his broad range of experiences with A Concise Natural History of East and West Florida (1775). A seasoned merchant seaman during The Seven Year's War, he sailed under British rule. After the war, he continued as a merchant traveling the coast from Florida to Canada. Suffering from a disease that left Romans in great fatigue, Romans found himself fulfilling many roles as a surveyor, at times working with renowned naturalist William Gerard De Brahm, to whom he built much bitterness toward for not being paid for services rendered. He earned a reputation as a botanist when thought to have discovered jalap. Getting caught up in the American Revolution, his cartographic, engineering, and surveying skills were called and looked upon favorably by the Continental Congress to help fortify the Hudson River. It was later noted that Roman's plans for fortification were inadequate and resulted in overspending and additional controversy.

Surviving his first wife who died shortly after childbirth, Romans married again later in life to a woman less than half his age. After the birth of their first child, he joined the Southern Campaign in 1780. It is said the vessel in which Romans sailed was captured and he became a prisoner of war, eventually dying in passage. With health and sickness always an issue in warmer climates, Romans synthesizes readings in medicine and direct observations about disease in the passage below.

Edited by Gail Busjahn, University of South Florida St. Petersburg

\section{Further Reading}

Cumming, William P. The Southeast in Early Maps. 3rd ed. Revised by Louis De Vorsey, Jr. Chapel Hill: U North Carolina P, 1998. 
Diamant, Lincoln. Bernard Romans: Forgotten Patriot of the American Revolution, Military Engineer and Cartographer of West Point and the Hudson Valley. Harrison, N.Y.: Harbor Hill Books, 1985.

Phillips, Philip Lee. Notes on the Life and Works of Bernard Romans. Deland: Florida State Historical Society, 1924.

Romans, Bernard. A Concise Natural History of East and West Florida. Ed. Kathryn E. Holland Braund. Tuscaloosa: U Alabama P, 1999.

I shall now treat of a subject in which I confess myself not to have so much skill as I could wish; I speak of it from such experience as my temper, inquisitive into the mysteries of nature, has furnished me with during my stay in this country; I mean the diseases most frequent in those provinces. But by way of prologue, I shall enquire a little into the universally dreaded, though chimerical unhealthiness of this climate. Dr. Lind[1] enumerates some proofs or signs of an unhealthy country, which are as follows, viz. 1st. Sudden and great alterations in the air, from intolerable heat, and chilling cold; this is perceived as soon as the sun is set, and for the most part is accompanied with a very heavy dew, and shews an unhealthy swamp soil; this is perfectly the case on St. John's river, and about Nassau-river, in East-Florida, likewise at Mobille, and Campbellton, in West-Florida. At Pensacola, and from thence East: there is little or none of this perceivable; at Orleans, and on the Mississippi I was not sensible of any sudden alterations of this kind: and on inquiry found it not be generally complained of. Neither of those provinces are so subject to this unhealthy variability as Georgia and Carolina, especially the last; however, I do not find that any person need be much under uneasiness about this any where, nor even a newly arrived European: the chief care necessary to such at seasons when these sudden alterations take place, is to avoid being exposed to the night air, and after sun set to add some more clothes to those worn in the day time; and if on a journey in the woods, never forget keeping a very large fire at night in order to rarify this dangerous air. His second sign is, thick noisome fogs, arising chiefly after sun-set, from the vallies, and more particularly from the mud, slime, and other impurities; this I never perceived to a great degree in any part of these provinces; St. John's alone is a very subject to thick nasty fogs of all kinds, the sea-side where soft salt marches are frequent is often troubled with these, and these marshes a little before rain emit a most horrid, and to me a suffocating stench; the northern part of East-Florida is very full of these kind of marshes, in Georgia and Carolina they cover a prodigious surface; the marshes in the south east of EastFlorida are of a different nature, and in West-Florida I remember very few of this kind; I have however, never heard any thing said contrary to a prevailing opinion of great salubrity in dwelling near the sea side, even among the thickest of these marshes; nor have I ever heard of any notice taken of the above stench by the inhabitants, except as being a certain indication of rain; where this kind of marshes are situate in brackish water, the situation is beyond doubt very unhealthy, the wan complexion and miserable mien of the generality of the inhabitants of such districts too plainly evinces it - We know by experience, that all fenny countries on every part of the earth labour under the same unhealthy calamity, but the comfort is, their areas are every where very small when compared with the more salutary situations which abound almost universally in every province, and in every climate. 
The third is, uncommon swarms of flies, gnats, and other insects, which attend putrid air, and unhealthy places covered with wood; the first of these is not common here, except at indigo works; and if these, according to my former caution[2] be little remote from the dwelling, I never saw nor heard of any bad consequences with regard to health attending them. I have already mentioned the bad effects of these voracious vermin on cattle of all kind at an indigo work; gnats, here called musquitos, are vastly numerous in some spots, but after we have passed some distance the brackish waters in every river, they diminish, and at last we find none; the Mississippi however is an exception, but on this river they are not in such plenty at the freshes as below, at the rigolets, on pearl river, and at the Riviere aux Boeufs, and on Dolphin-island, likewise in Santa-Rosa bay, and in the bays of St. Andrews, St. Josephs, and at St. George's sound and islands, they are intollerable, and all the sea coast of both provinces is exceedingly pestered with them. I travelled across the peninsula in 1769, in the months of June, July, August, and September, but found none at all in the interior part; I never heard these being attended by any fatal disease except their troublesome bites, which sometimes cause inflammations, especially in the legs; but the inhabitants of the western province so effectualy fortify themselves against those vermin with musqueto nets, tents, and Baires, [3] that whether at home or travelling, they are not in the least danger from the attacks of this terrible and bold, though dimunitive enemy, whose destruction gradually takes place as the woods daily diminish; in very dry hot summers, scarce any of these vermin are seen; a very dry hot air causing the deaths of numberless animaculæ: of every kind, their effiuvia, even of those that are imperceptible to the naked eye, arising or exhaling from ponds, marshes, swamps, \&c. must spread a great quantity of noxious vapours through the atmosphere,[4] and consequently corrupt the air, and spread disease throughout their vicinity; this misfortune will likewise cease on opening the country, till then let me advise every new comer, particularly a person of a gross habit of body, to be careful of his constitution, a wine-bibber or rum guzzler, with such a plethoric habit, can hardly avoid falling a prey to this bad air.

His fourth, is the quick corruption of butcher's meat, \&c. this, if the case at all in any of these provinces, is not common, I remember indeed to have heard a complaint of this happening at Pensacola in 1765, which was a sickly season, but in all my journies through these provinces I never experienced it, on the contrary I could always by some means or other preserve my venison, or beef, when there was a necessity for doing it.

The fifth reason, says the Doctor, is a sort of sandy soil, among others he says, such as that at Pensacola; I beg leave to inform the Doctor, that the sand about Pensacola, and throughout these provinces, is a coarse, gritty and gravelly sand of various colours, though chiefly red and white, that on this sandy soil many excellent salubrious herbs grow, which serve as food to innumerable herds of cattle, and when cleared they are improvable by culture; this is not the case with the hot sandy desarts of South-America, Africa, and Asia, over which the samiel wind passes, nor do I believe that the oldest person in Florida remembers any sudden, hot and suffocating gusts, or blasts, from which he has ever been obliged to turn his face in order to draw breath; there are no open plains of sand in North-America, they are all covered with trees rooted in the lower strata of these sandy tracts; the only plain of sand I know without trees, is at, or near the head of St. Lucia, in East-Florida, which however is not extensive, and to it numerous herds of roe-deer resort during night from the adjacent woods; I think, therefore, that neither of the Floridas have any ill consequences to dread from their land winds; moreover, if we consider, that the land-winds come from the west and north-west; geography will tell us, that they range over innumerable acres of 
oak land, consequently clay ground,[5] and that only the sea coasts, and from twenty to about an hundred miles off, are any ways sandy; which being so constantly fanned by the wholesome seabreezes, (so remarkable in these provinces) could not have any fatal effects, even if the ground was of the nature of the Lybian desarts; thus we see again how men reasoning from mere theory, are liable to commit mistakes.

To treat of the diseases to which the human frame is most liable here, in the same regular manner, as I believe I have done of every preceeding article, I will divide them into two classes, viz. acute and chronic, and the first again into two orders, viz. those of the summer, and those of the winter.

Fevers are the first of the summer diseases; the ancients have ages ago made an observation, that the season of the reign of this terrible disorder was always preceeded by an atmosphere laden with great heats, and much rain, for some time; the modern writers seem to me to be generally of the same opinion; this is exactly the case in all the southern provinces; for fevers begin to take place in some districts more, in some less, about the latter end of July, and in August, and continue throughout September, and part of October, just the season immediately succeeding our greatest rains; and most violent heats; here I will notice a[6] remark which I have read long ago, and I find it confirmed in all climates, "That the middle of the third month was observed to be the period of the greatest rage of epidemical disorders." Those districts which lay near to low rice fields, particularly in back swamps) and to such indigo works, where the planter is obliged to make reservoirs of water, are most liable to these disorders, after, and during the latter part of an excessive drought; because in those neighbourhoods the air is at such times most prodigiously loaden with corrupt moist effiuvia; for this same reason, cool rainy summers will make those places more healthy than dryer spots, because during such a season all the above mentioned noxious exhalations do not take place in so great a degree, and the air is kept cool by the frequency of the showers; however such situations will never be so common in the Floridas as in Carolina or Georgia, the quantity of good wholesome fresh running water being infinitely greater, and consequently little necessity of making stagnating ponds or dams.

It must be allowed, that all fevers however dissimilar in appearance, proceed from the same origin; nature only works with more or less violence to rid herself of what is detrimental to her.

The Ephemera, or day fever, occasioned by a meer increase of the velocity of the blood, by means of a fit of drunkenness, or debauch, or originating from violent exercise during the heat of the day is too frequently seen here; but as it is seldom of a longer continuance than eighteen or twenty hours, it has not often dangerous consequences, and may be avoided by every person; I shall content myself with barely observing, that some cooling acidulated liquid aliments will soon abate its violence, bleeding may likewise be of use to restrain its force.

The continual fever, or inflammatory fever, is sometimes, though rarely experienced in this climate, but seldom attended by those dreadful symptoms and fatality, which accompany the same kind of fever, though of a more violent class in the countries immediately between the tropics: this, in its common form lasts about ten or twelve days, beginning to abate its violence in general after the seventh; the fourth or fifth is often fatal. I am persuaded, that whenever the yellow fever has made its appearance in the Floridas, it was imported from Jamaica or Havannah, as was the case in 1765 , which (by the way) was almost universally an unhealthy Æ Æra, as well in Europe as 
elsewhere. This continual fever begins with an excessive heat of the whole body, continued, though not violent head ach, great drought of the tongue and palate, and consequently a continual desire to drink; those people who die of this disorder, generally depart on the fourth day, and I am of opinion, that few are carried off by it, except such as are kept too close confined from the fresh air: I would recommend the keeping the sun out of the room, but to admit as much air as will gently ventilate it; a cooling diet, such as rice gruel, barley water, infusions of baum, or sage, and lemon ade, which is lime juice, water, and very little sugar; lime juice, syrup of lemons, and currant jelly should moderately enter into every part of the patient's diet; avoid all salt, spices, spirituous liquors or generous wines; a gentle purge of glauber salt, with a few grains of kermes mineral, and some drops of oil of mint is generally given on the first appearance of the disease; the effects of this are forwarded by frequent draughts of warm chicken broth. During the operation of this, avoid all acids: bleeding (especially if the disease makes a violent attack, and the patient is of a plethoric habit) is indispensably necessary, the patient ought by all means to avoid motion, and notwithstanding the above caution of admiting air in the room, keep himself covered, and be careful not to throw his bed cloths aside. If the symptoms abate after the above mixture, emetics are commonly subscribed; if it still continues, particularly if attended with delirium, lethargic symptoms, or their reverse, blisters are applied; and in great watchfulness some laudanum is used; if worms are suspected, an infusion of Indian pink root,[7] (a very common plant here) leaves, wood, and all, is made use of as tea; but this plant possessing a pretty strong narcotic quality, ought to be used with caution: in excessive heats some grains of sal nitri are added to the liquors administered to the patient, and as soon as the fever begins to abate, some orange, lime or lemon juice, saturated with salt of wormwood, is given by a small tea-cup full every two hours.

The yellow fever being sometimes imported here, it may be necessary to describe this Proteus among diseases, which I have frequently seen, and which I myself have suffered in Jamaica under one of its various forms. I chuse to follow the description of Dr. Rouppe, in his de morb. navigant, as quoted by Dr. Lind, because I find no other author who has done it so exactly, and if I had not seen his account I should not perhaps have recollected half the symtoms he mentions, altho' I now perfectly remember to have seen that dire distemper in every shape he paints it in. He seems to speak of it as an illness to which seamen only are subject in that climate (Curacoa;) he may have been induced to think so by the disorder not raging on shore; the florid complexion of most of the people in the island sufficiently shewing it to be a very healthy spot; but I find by his description, that it was the real yellow fever contracted at St. Eustatius; he calls it the putrid colliquative or spotted fever; it raged in the Dutch ship of war Princess Carolina, on board of which this physician arrived at St. Eustatius on the 1st of August, 1760, on the 11th they sailed from thence for Curacoa, which harbour they entered on the 19th, and then (whether he means on the passage, or the very day he arrived, seems doubtful) twenty people were sick, some of these had headaches without fevers, and some were afflicted with a true bilious cholic; but they were by an easy cure again restored to the enjoyment of their former health: the sense of his account of the disorder, I take to be as follows, viz. [....][8]

The French call this disorder mal de Siam, supposing it originally imported from thence into the islands; the Spaniards vomito preto, or black vomit; the Dutch geele koorts, which last conveys the same idea as the English yellow fever. 
In general, when fevers are violent, the practice which prevails at present, is to have recourse to antimonial medicines, and as soon as a remission is brought about: the bark is administered in large doses.

Intermittents are endemial in all low situations, thus we see in all the provinces to the southward, particular places remarkable for a continuance of this disorder in them, such as more especially Jacksonburg, in South Carolina, Savannah, in Georgia, Rolles-Town, and most of the settlements on St. John's, in East-Florida, at Campbell-town, near the mouth of the Escambe and at Mobile in West-Florida; this disease attacks people much in the same form as the continued fever, the first fit frequently lasting three days without intermission; physicians treat it nearly in the same manner as the last, but I have observed, that they are very averse to taking blood from a patient afflicted with this disorder, saying, that bleeding is a sure way to prolong the disease, although sometimes a small matter of blood is taken from people of a very gross habit of body, when the returning fits seemed to continue longer in point of time than at the first, the same diet is observed as in the continued fever, except when the patient is very weak, when strong broths well separated from the fat are frequently given; if delirious, or comatose symptoms with pains in the back, \&c, make their appearance, cooling medicines are used, during the paroxysms, Doctor James's powder or other antimonials, and on intermission the bark in copious doses is administered with success, and in obstinate head-aches recourse is had to blisters.

This is a very tedious disease, and whoever is afflicted with it should not too soon judge himself cured, but continue taking a bitter infusion, composed of the bark of the root of the magnolia major (which the French on the Mississippi substitute in lieu of Jesuit's bark) with Virginia heart, snake root, rue, sal absynth, and pink root, in good Madeira orLisbon wine.

People in general, suppose them even obliged to remain on the sickly spot during the fatal season, which is autumn, may by care, in a great measure shun this tedious illness, such as living on a more generous diet, especially animal food high seasoned, and a moderate glass of wine; avoiding a too great exposure to the then frequent sudden changes of air. They ought to use the cold bath often, wear garlic and camphire in the pockets, not expose themselves to rain, and above all keep warm and dry feet, and if got wet by rain not to change their clothes too suddenly; never go out of a morning fasting, but before you go to work, business, \&c. eat a piece of bread, and drink a glass of the bitter infusion; avoid the night air, and keep some fire in the house, particularly in the mornings and evenings to rarify the damp air in the rooms, especially in the bed rooms which ought never to be on a lower floor, and should be in the eastern parts of the building exposed to the morning sun: by observing these rules the constitution of the human body will be less disposed to receive the impressions of a bad air.

An excellent thing to be given the negroes on a plantation before they go to work, is a wine glass full of the above bitter ingredients, and garlic infused in rum; and they should be encouraged to chew and smoke tobacco.

When a person is seized with a fit of the ague, he ought by no means to delay going to bed, and drink a draught of lime juice, and powder of chalk, while it is fermenting in the glass; this will bring on a sweat, and shorten the fit, or in the hot fit use some opiate if the patient is not delirious, this ought to be done as often as the paroxysms return. 
The nervous fever, likewise called the slow fever, is known by a small, quick and low pulse, and by not affecting the patient with such violent heats as the others fevers, but with greater oppression about the prœcordium; it does not make them so thirsty; the tongue is at first unusually moist, and looks white, though at last it becomes dry, and looks brown or inflamed; continual heats are felt in the palms of the hands, heats and chills return alternately very quick, a copious clammy weakening sweat, excessive lowness of spirits, restlessness, being drowsy without power of sleeping, pain and giddiness of the head, ringing in the ears, and if it lasts long, the tendons are often affected with a sort of cramp; deafness, deliriums, continual lethargic fits; insensibility and stupor are the constant attendants of this disorder when in its last stages.

This is a most treacherous disorder, and by affecting the sufferer with only slight symptoms of weariness and weakness, attended with frequent yawnings and stretchings, a slight giddiness and loss of appetite, and a great heat in the forehead, makes people neglect an early application to the physican, and thus they endanger themselves much, though in people of a robust constitution who are much exposed to the sun, it will often appear for the first day or two with violent symptoms; this fever will last sometimes for twenty days or more without any apparent abatement; it generally attacks people who have been exposed to unusual fatigue, or such as are naturally of a weak constitution. Vomits are the remedy to which recourse is most usually had in this disorder.

Physicians steadily, and almost totally avoid bleeding and purging, till after a free use of the Ipecacuana, and even then their cathartic prescriptions are rarely any other than manna and salts, and after the gentle purges obtained by this method, they order a free use of rich chicken broth, and the above described juice of lemons saturated with sal absynth: this they generally continue until the disease changes into an intermittent fever, and then treat it in the manner last mentioned; frequently also applying blisters.

This fever more particularly than any other disorder, bears hardest on the patient towards sunset. The diet commonly prescribed is sago, chicken broth and panado, with some small matter of wine and loaf sugar in the first and last; infusions of sage and baum, together with wine whey, are the drink mostly thought proper during the continuance of this disorder.

The use of bark is generally blamed as productive of dropsy; jaundice, the ague cake,[9] and other inveterate chronical disorders, but it is certain that the bark is blameless; it is the fault of the physicians, who too late and with too much caution use this blessed remedy, which seems as purposely designed by Providence to relieve us in those tedious disorders; or it is that of the patient himself, who, prejudiced against this excellent remedy, refuses to take it till it is too late, and thereby brings upon himself the above diseases, which are consequences of the fevers, not of this great specific. The above mentioned fevers and unusual hardships in travelling, \&c. as well as excesses at plentiful tables full of variety, often bring on a severe bloody flux especially in autumn, and if this makes its appearance with hard dry and bloody stools, the disease is dangerous; brisk purges and clysters of Castile soap, and some of the hot seeds are used to expell these; when the desired end is obtained, gentle emetics are called in; I have known people find great relief from a decoction of logwood and pomgranate skins, others again it would not help in the least; a new honey comb inclosed in an apple scooped out, and then roasted before the fire, has often proved a speedy and very effectual remedy; calcined hartshorn, a nauseous medicine, is nonsense; bark of sumach is a good medicine, but there being a dangerous kind, it ought to be gathered by a skilful 
hand; the bark of the liquidambar styraciflua; aceris folio mentioned in page 20 , together with the gum exuding from the same tree, is generally found efficacious; a wine glass full of the juice of lemons mixed with some common salt has often proved a most excellent, safe, and general specific; the frequent chewing of cinnamon and camomile flowers, especially when a weak stomach vexes the patient, has a noble effect; avoid all vegetable food except rice, eat roasted rather than boiled flesh; salted beef need not to be avoided; use often veal, jellies and salop; use a great deal of mustard; I know by the experience of many as well as my own, that Dr. Barry's observation of vegetables not being so easily assimilated as animal food, is in the strictest sense universally true, and in an obstinate continuance of this disorder, vegetables even our common wheaten bread are not at all digested, but most generally pass through the body unaltered. When this disease changes into a chronic habitual flux, it will be necessary to use pills of equal parts of rhubarb and ipecacuana, mixed with some liquid opiate, and use weak lime water for common drink: if this does not prove a specific, let the patient be removed to some other clime, for no remedy will affect that disorder in the same climate, where it was originally contracted, claret or port ought to be their constant drink in this disease, and spirituous liquors ought by all means to be avoided; rum, a cursed bane of health and of society; is too often and indiscriminately applied to every disease as an universal arcaum.

The cholera morbus is likewise a consequence of intemperate meals, and when it is not occasioned by any food peculiarly repugnant to the stomach it often proves fatal.

Debauch of every kind, particularly unseasonable sitting up, is most frequently productive of some of the most dreadful disorders, and excessive passions of the mind sometimes produce the same effects.

Excess in venery is generally productive of the most violent and obstinate disorders, principally inflammatory fevers, and obstinate fluxes.

There is a disease which the French call La Tytanose, which affects people in the western parts of Florida, and will attack them with prodigious violence upon being wounded even in the slightest manner: if during the hot months a splinter be run into the flesh, the patients are attacked with violent contorsive spasms, and generally die in about eighteen or twenty hours.

I never saw any person afflicted with this dreadful disorder, but from the similarity of the name with the latin Tetanus, and from my being told, that opium and camphire are much used to procure relief, I take it to be the locked jaw, with which I saw a young man die at Mobile, Mr. Lind[10] recommends copious external applications of opium, and the cold bath; and gives some imperfect account of mercurial ointment having lately proved an efficacious remedy; the hint was perhaps necessary to be inserted here.

Angina Suffocativa, or the putrid sore-throat, sometimes appears here, this is a contagious distemper, and rages in America mostly among the youth; it generally begins with a slow fever attended with great lassitude and a low pulse; this is succeeded by a sore throat with white spots near the uvula, and if it be not immediately taken notice of, the patient soon becomes past hopes, and generally dies within 24 hours after the first severe attack of the fever; the physicians in Carolina and Georgia prescribe first mercurial purges, and order a gargle of borax, dragon's blood 
and Armenian bole in vinegar and honey; and the throat is anointed frequently by help of a feather, with a mixture of balsam of sulphur, tincture of myrh, honey, loaf sugar, and yolk of eggs; the principal part of the cure is to attend the disease early, the least neglect being dangerous.

The dry belly-ach is a very painful and tormenting disorder, though rarely fatal; it is occasioned by cold damp lodgings, and being exposed to the night air; but most frequently in all climates by an excessive use of the vegetable acid juices, which are all extremely astringent in their nature: and when this disorder proceeds from too liberal an use of punch, rheumatic pains and paralytic affections of the nerves are its constant consequences and attendants, with loss of the proper use of limbs: (often for life) the most unusual symptoms are the vomiting of bile, with the most obstinate costive habit imaginable; and when stools are procured, the excrements are excessive hard and in round balls like horse dung: all this is attended with the most excruciating pain in the bowels, and a clammy sweat: the method of cure is by administering emetics of the antimonial kind, which often also procure a stool; this is the only thing that can relieve the poor sufferers; the warm steam of hot herb baths, clysters of the tinct. Thebaic. in luke warm milk and emollient plaisters in which opium enters, applied to the stomach a belly; bitter purging salts and manna, and infusions of sena leaves, after middle vein is stript out of them; in the severe attacks of the pain, opiates are used, and too often that cursed arcanam of the vulgar among the English:

I mean rum and other distilled spirits, which in this disorder too often pr fatal poisons; the oil of Palmæ Christi, by three or four spoonfuls has so times proved effectual; oil of almonds and of olives, have been given success; after all medicines had failed, I once applied to a mulato woman who was a noted empyric in the island of Curacoa, where I was attacked by this distemper: she ordered a clyster of sweet milk, tobacco and brown sugar which gave some slight relief, but after a while the painful symptoms of the disease seemed to be as excruciating as ever; she then gathered some handfuls of the leaves of a shrub which is there called Wild Carpat;[11] these she boiled like spinnage, and made them into seven or eight balls of the size of walnuts, put them in a plate, and poured oil olive on them, and a little pepper; this kind of salad she made me eat with a piece of bread, when I observed to her, that she ought to have added vinegar to have made a perfect sallad; she answered, that vinegar in my case was poison; in half an hour after the use of this mess, a stool (the first in twenty-three days) was procured, which was followed by five or six more that very afternoon; and she then gave me for some days an intensely bitter mixture, in which I perceived the juice of aloes predominant, but could not learn the composition. This kept me in a lax habit of body, and in about fourteen days I was enabled to pursue my ordinary avocations; camphire and opium enter into all the purgative prescriptions I have seen ordered in this disease, by the physicians of the south.

There is an instantaneous fatal disorder which the French call un coup de Soleil, i.e. literally, a stroke of the sun; of this I remember one instance during my stay in West-Florida, when it killed a child of about twelve years old on the spot between the hours of eleven and twelve in the forenoon, the time, as I am informed, in which it always takes place; by instantly applying cold water to the crown of the head, I am told, its fatality is prevented; likewise by cupping the crown of the head: what its symptoms are, I have not seen, but by the descriptions, I take it to be a fever, which so violently attacks the patient, that it causes instant death. This disorder occurs very seldom, and as it is so very easily guarded against, persons who are attacked by it, are in a great measure blameable for their own misfortune, particularly if they know the country; the French, one 
and all, put a single piece of clean writing paper between their hat and head during the hot months, to ward off the attacks of the coup de Soleil.

These are the diseases, which occur during the hot seasons; there is likewise a fever, in which the patient is continually affected with defluxions of the head: this appears in the late winter months, and during a wet spring; it is called a Catarrhal Fever: this disease is not frequent, but when it appears, it is generally treated like other fevers, except that bleeding is more freely used.

The pleurisy also makes its appearance sometimes in winter. Moderate or copious bleedings from the arm according to the degrees of violence of its attacks are immediately used: if looseness and gripes attend the pain, blood is taken away often, and in small quantities; the patient is kept moderately warm, and on no account suffered to uncover; the first medecine is commonly a cooling purge; gentle sudorifics are likewise administered; frequent hot baths for the feet are also prescribed, but very cautiously applied for fear of his catching cold. After the operation of purges and sudorifics, gentle antimonials are used, and a light easy digested diet, with infusions of hyssop, sage, or baum, follow in course; likewise swallowing of living wood-lice: and in case of costive symptoms, clysters are used; on a continuance of the pain in the side, a moderate blister or drawing plaister is put to the part;- much coughing, which causes a watchfulness, is removed by opiates: in feverish symptoms the disease is treated as the other fevers; spirituous liquors are to be avoided by all means.

During some winters, a Peripneumony also visits a few people here; the method of cure is the same as for the pleurisy: it is said to be more dangerous than the pleurisy, particularly if copious bleeding is not made use of as soon as the patient is affected. In this disorder there is generally a freer access of air allowed than in the last, and the patient kept almost in a sitting posture; it is said that the steams of warm water drawn into the lungs in this disease, is a powerful help.

A compound of the two last disorders, called the Pleuro-peripneumony, is likewise sometimes heard of, and is treated as the last.

In Georgia I saw one or two instances of a disorder among blacks, to which the people give the odd name of the pleurisy of the temple, of the forehead, of the eye, and so on; I am told they have a pleurisy for every part of the head. It is violently acute, and, as I am informed, proves sometimes fatal in ten or twelve hours time; if immediately on its attack, a quantity of blood is not drawn from the arm, for the rest this disease is treated like a pleurisy.

The chronic diseases are dropsies, consumptions, hemorrhoidal and habitual fluxes, relaxed and bilious habits of body, ruptures, worm-fevers, and among blacks the leprosy, elephantiasis and body yaws; which last in Carolina is called the lame distemper; the first five of these are often best removed by a change of air, as the most efficacious medicines often prove of no use against the obstinacy of the disorders in the climate where they first originated.

The dropsy most frequently seizes a patient after an obstinate intermitting fever, where the use of the bark has been too long delayed: in this disorder the ordinary prescriptions in these countries is syrup of squills, and the common diuretic salt; with these the patient is confined to dry food, and from spirituous liqurs; such vegetables as turnips, radishes, \&c. he is allowed to indulge in: Dr. 
Lind says, that exciting a slight salivation, may be of help in a tolerable sound constitution, perhaps none of the chronic diseases are more relieved by change of climate than an obstinate dropsy. A consumptive habit of body, particularly where the cough is very obstinate and frequent, and when bilious stools, with a great hardness of the lower belly affect the patient, or when a continual fever emaciates the poor sufferer, he is in a dangerous way, and a remove to colder climates is hardly adviseable; I have known such people relieved by making frequent short voyages to sea in moderate climates; but unless proper remedies are also made use of during these voyages, the fever returns almost directly on relanding; frequently after one or two of these voyages the patient feels himself better; if he then retires to a milk diet, and freely indulges himself in fruits, utterly avoiding all manner of drugs or medicines, he may find relief, and even a return of constitution; frequent doses of flour of brimstone, and cooling the water he drinks with sal nitre, are of use during this course: likewise the patient ought with the greatest care to avoid exercise; the stiller he keeps himself the more hopes of recovery there is. The fever which attends this disorder is of such a nature, that here the use of the bark must be carefully shunned, as it has been during long practice, and by frequent experiments of very able physicians, found to be a sure poison in this disorder. The Spaniards wear the nest of the great travelling spider sowed in a rag about their necks as a sure way to assuage a hectick fever, and I think with great success: it is a matter of surprize to see how perhaps a thousand animalculcœ which are in perfect life in one of these nests, at the time of its being put round the patient's neck, will in the course of about thirty hours be perfectly pulverized by meer dint of the heat of the body, which these young Spiders seem in a peculiar manner to attract. In hardness of the belly in this disorder most of the Creoles use hard and frequent rubbing it with a warm hand dipt in oil or hogs-lard, Quere bears oil being so very subtil and penetrating, would it not be preferable in rubbing?

The hœmorrhoidal flux is very frequent here, and was it not so very troublesome an attendant, it would be looked upon as a beneficial event. Persons who are attacked by it are generally certain of not falling into the more dangerous diseases occasioned by obstructions of the Viscera in hot climates; the greatest danger attending it is that of the patient's falling into an habitual flux, which is a most tedious and troublesome disease, and that although the patient has no other complaint but the frequent necessity of going to stool and is but seldom troubled with an involuntary expulsion of the fœces; this disease is almost always a slow though sure harbinger of death by its continuance for years, draining to the very last drop of moisture from the sufferer, who being left a meer skeleton, is as it were carried off in the manner of an expiring candle-snuff; yet those persons, who have been opened after death have been found with all the inward parts perfectly sound, and thus the faculty is left in the dark without any way to account for this disorder; I have heard of people of a very robust constitution with whom it has continued above twenty years; no disease is so frequent; it almost always attacks people who have suffered much from frequent sickness or severe fatigue; and its obstinacy is such, that it will yield to no remedy whatever in the climate where it originated; I have myself been attacked by it first in the province of Georgia, in consequence of the great fatigue I underwent in my frequent long and wearisome journies by land; no astringent of any kind, not even the long use of rhubarb and ipecacuanha was of any the least service to me; vain was every medicine against this obstinate malady; opium was recommended to me as a specific; this I took at length in incredible doses but the relief was only momentary; after the short reprieve obtained hereby it returned with tenfold violence and obstinacy: if then I was unhappy enough to use opium during this attack it was of no use whatever, but obliged for the next time to seek respite from a double dose, the cold bath I found of some slight benefit and when I 
was at the proper season in any part of Florida, where the coco-plumb[12]grew in abundance, by freely eating this wholesome fruit I was relieved for that season, and no

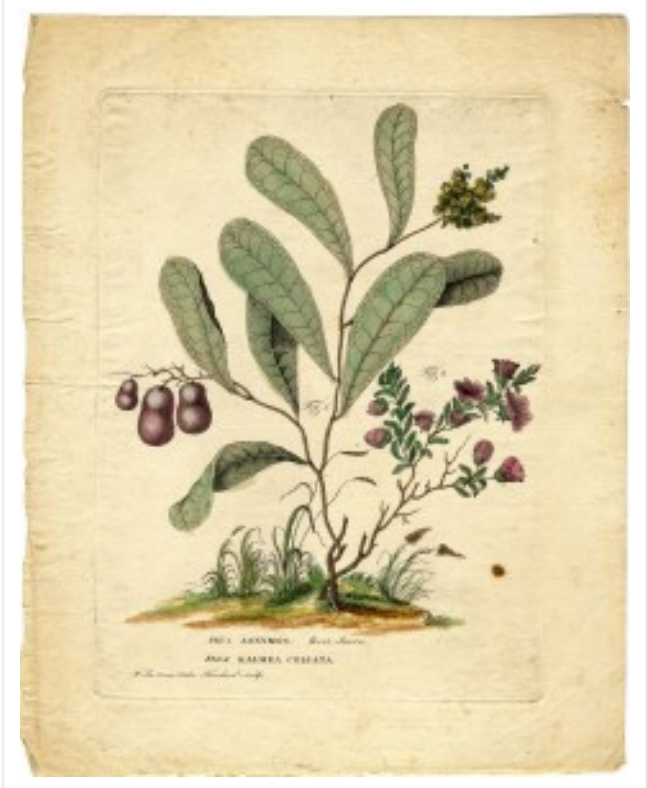

\section{- William Bartram, Kalmia celiata (coco plum). Courtesy, American Philosphical Society}

sooner was I obliged to abandon this excellent remedy, but the disease again prevailed. Thus was I harrassed for about eight years when I changed climates by coming to New-York; here likewise all medical prescriptions failed, till at length I found that a decoction of the bark of Semi-Ruba and Terra japonica in the proportion of half an ounce of each to six pounds of water being boiled down to one sixth, was an effectual medicine after the change of climate, which last alone must not be relied on: one quart of the above decoction in the quantity of a wine-glass full taken morning and evening cured me; but relapsing again after about three months I got another quart, with the two first glasses of which I took a small pill of crude opium, and by two more glasses full I found myself again restored to my natural habit of body.

An entire relaxation of the solids, and a bilious habit of body is another common affliction of those, who have suffered much by the diseases of hot climates; the constitution is in such people so decayed, that it seems as if every moment would be that of dissolution: the stomach is weak, their complexion is nearly that of a sufferer by the jaundice, and hardly any food especially greens and salads are found digestible; if the dry belly-ach has been their frequent attendant a paralytic contraction of the limbs is the final consequence of that malady: others again will frequently vomit clear bile and be very costive having the abdomen exceeding hard; for all these complaints there is no better cure than a change of climate, and when the patient begins to feel any benefit from the difference of air while at sea, I would recommend a plentiful and constant use of chamœmile flowers, chewing them in the same manner as people do tobacco; this, however disagreeable to most palates at first, becomes in time as agreeable to the mouth as it is grateful to the stomach. The use of Elixir Vitrioli in the quantity of fifteen or twenty drops taken every morning fasting and again an hour before dinner; and the moderate use of a glass of generous wine is not amiss to 
such sufferers: animal food, especially mutton, is the most suitable diet, and in case of an obstinate costiveness use the Elixir Aloes often at night or in the morning; the cold bath, especially of salt water, is very beneficial to such sufferers.

Ruptures are pretty much complained of on the banks of Mississippi; I have observed likewise that they are a good deal frequent in Georgia and in Carolina: what can be the cause of a disorder of this kind being frequent I know not, but I find in a pamphlet which gives a superficial description of South-Carolina the following way to account for it, "the obstructed viscera being swelled beyond their natural size, the intestines are too much confined, and by nature of the aliment and bad digestion being frequently distended with wind, it is not to be wondered at, that they often pass through the rings of the abdominal muscles."

The Worm fever which is common through all America, especially from Pennsylvania southwards, is not so common here as in Carolina, Georgia, \&c. the reason I take to be because the sweet potatoe is not so universally used for food here as elsewhere; children suffer most with it; though it sometimes affects people of all ages. When a fever obstinately withstands all medicines it may almost be depended upon, that this obstinacy proceeds from worms; the stincking weed which is known by the name of Jerusalem Oak? and in those provinces is the most efficacious vermifuge, and the safest medicine especially for children; a spoon full of the expressed juice of the whole plant taken on an empty stomach is found to be a sovereign antidote; the Lonicœra I have already mentioned as to its qualities; if the worms are suspected to be lodged in the rectum, clysters of a decoction of tansey, onions, garlick, rue, worm wood, and such like in milk are of good effect; a plaister of pulverized Aloes, oil of rue, or worm-wood, with powder of the bitter gourd and ox-gall applied to the navel is also of good effect: I would recommend the use of animal food, particularly rich fish-soups highly seasoned with garlick or onions, and it will be proper to avoid all kinds of farinaceous vegetables except wheaten bread: above all the potatoe and pumpkin ought to be shunned as poison. A loathsome disease appears some times among the Negroes after severe acute disorders, especially if the patient has been obliged to keep his bed long, likewise after a violent exercise has brought on a surfeit: this is called the Elephantiasis from the swelling of the feet and legs; it is most frequently seen to affect one leg only; in the first stages of this disorder the patient becomes wretched through excessive lassitudes which bring on an emaciation of the body, then the corrupted juices subside into the leg or legs and feet, these swell, the skin becoming distended, shines and shews the distended veins every where below the knee; now the skin by degrees loses its gloss and becomes unequal and something scaly; after this chaps make their appearance, the glands are stretched and the scales are daily enlarged, appearing as hard and callous as the hide of an Alligator, notwithstanding which the slightest prick of a pointed instrument will cause the blood to exude; this disease affects neither the appetite nor the digestive powers of the body, on the contrary the patient in this and chearfulness of spirits resembles the healthiest of men, and the inconvenience of his heavy leg only prevents his ability for the more laborious part of his duty.

No manner of cure has yet been found for this cruel disorder, but the patients often live to a very advanced age under the pressure of its yoke, even when it has been contracted in early youth; it is said that the amputation of the affected limbs is no cure, for the disease will immediately attack the sound leg; this I find also asserted by Hughes in his Natural History of Barbados. 
I have seen three or four instances of the disease called body yaws (in the Islands) and in Carolina the lame distemper, this is said to proceed from hereditary venereal taints; it appears in cancerous corroding sores in the mouth and throat, and spreading ulcers together with fleshy protuberances chiefly on the face, breast and thighs, with a swelling of the skin and kneebones, and commonly corrodes the Cartilages of the nose, its first symptoms shewing themselves about the throat and palate, have caused ignorant people to mistake it for the Angina Suffocatitiva before described: Mercurial medicines are used against it, afterwards diet-drinks of China root, nut-grass, \&c. the sores in the mouth are often to be rubbed with a feather dipt in syrup of roses to an ounce of which two drops of Sp. Vitr. have been added: unctuous, salt, spiced meats and spirituous liquors are absolutely to be avoided; frequent sweats are also prescribed and a great care against catching cold. The Leprosy so called, whether the same as was the cause of proscription to the unhappy patients under the Mosaic laws I shall not pretend to determine; certain it is, that it is a nauseous, loathsome and infectious disease some times seen among the blacks; this appears first with the loss of beard and hair from the eye-brows, swelling of the lobes of the ears, the face begins to shine and brown protuberances appear thereon, the lips and nose swell to a monstrous size, the fingers and toes will in the end drop off, and the body becomes at last so ulcerated as to make the poor incurable patient really a miserable object of pity.

[A "topographical description" of East and West Floridafollows ....]

[1] [James Lind, An Essay on Diseases Incidental to Europeans in Hot Climates ...] 2d edition p. 1 ch. 4 sec. 2 p. 137 et seq.London 1771.

[2] Page 139 [Romans' pagination, here and following].

[3] Baires are a tent made of a light coarse cloth, like canvas gauze, called by the French villemontiers.

[4] See page 15 of this volume.

[5] Excepting the few hammocks near the sea, which are oak land, but most of them sand.

[6] [Alexander Bruce], Inquiry concerning the cause of the pestilence, and the dieases in fleets and armies.London 1759.

[7] Lonicœra.

[8] Six paragraphs, from Louis Rouppe, De morbis navigantium .... (1754), deleted.

[9] A hardness in the region of the spleen, one of the consequences of long continued fevers, and by the Dutch Creoles distinguished by this name, they call it in their own language koek in de buyck, or simply de koek.

[10] Hot Climates, second edition, page 285-286. 
[11] Carpat, is the Dutch name of Palma Christi; I have long in vain tried to find the shrub, from which these leaves were taken; all I know of them is, they are Lanceolate, of a lucid green, and boil very tender.

[12] Chryso Calanus [Chrysobalanus BR]. 